\title{
A STUDY OF THE HYPOLIPIDEMIC AND ANTIOXIDANT ACTIVITIES OF WHOLE PLANT EXTRACTS OF IPOMOEA AQUATICA FORK IN EXPERIMENTALLY INDUCED HYPERLIPIDEMIA IN RABBITS
}

\author{
AZIZ SAHID ${ }^{1}$, GOHAIN KALPANA ${ }^{2}$ \\ 1,2Department of Pharmacology, Assam Medical College, Dibrugarh, Assam \\ Email: drshahidaziz86@gmail.com
}

Received: 12 Jul 2016 Revised and Accepted: 23 Aug 2016

\begin{abstract}
Objective: The aim of the study has been to investigate the possible hypolipidemic and antioxidant properties of the whole plant extract of Ipomoea aquatica in experimentally induced hyperlipidemia in rabbits.

Methods: Ethanolic extract of I. aquatica whole plant (EEIAWP) was prepared by percolation method. The extract was evaluated for hypolipidemic and antioxidant activities using $400 \mathrm{mg} / \mathrm{kg}$ body weight per day in a high fat diet induced hyperlipidemia in rabbits. The results were analyzed using one-way analysis of variance (ANOVA) followed by Bonferroni's multiple comparison tests and compared to the normal control, experimental control and the standard drug (atorvastatin $2.1 \mathrm{mg} / \mathrm{kg}$ body weight per day) groups. The results were expressed as mean \pm standard error of mean (SEM). Values with $p<0.05$ were considered significant.

Results: Oral administration of EEIAWP in the test group showed a significant reduction in the serum levels of total cholesterol (TC), triglyceride (TG), low-density lipoprotein cholesterol (LDL-C) and a significant increase in the high-density lipoprotein cholesterol (HDL-C) when compared to the experimental control group. There were also significantly elevated catalase and superoxide dismutase (SOD) activities and significantly lower malondialdehyde (MDA) levels in the test group compared to the experimental group. Similar results were also found in the standard drug group.
\end{abstract}

Conclusion: The results of our experiment demonstrated that EEIAWP possesses significant antihyperlipidemic and antioxidant activities and hence could be a potential source of medication as an adjuvant to the existing therapy for treatment of dyslipidemia.

Keywords: Ipomoea aquatica, Hypolipidemic, Antioxidant property

(C) 2016 The Authors. Published by Innovare Academic Sciences Pvt Ltd. This is an open access article under the CC BY license (http://creativecommons.org/licenses/by/4. 0/) DOI: http://dx.doi.org/10.22159/ijpps.2016v8i10.14059

\section{INTRODUCTION}

Cardiovascular disease is still the leading cause of death in most parts of the world. Epidemiological studies have established a direct relationship with serum cholesterol, and coronary artery disease [1]. Hyperlipidemia is one of the main causes of atherosclerosis and atherosclerosis-induced conditions, such as coronary heart disease (CHD), ischemic cerebrovascular disease, and peripheral vascular disease [2]. Obesity [BMI $\left.\geq 30 \mathrm{~kg} / \mathrm{m}^{2}\right]$ is one of the main determinants of the preventable burden of diseases. It results from excess consumption of calories/energy compared to expenditure thus impacting health. Globally, children, in particular, are gaining weight, which tracks into adulthood thus increasing the likelihood of adult diseases such as type 2 diabetes, cardiovascular disease (CVD), hypertension and polycystic ovarian syndrome (PCOS), etc. later in life [3]. In 2013, the American Medical Association classified obesity as a disease [4]. Hyperlipidemia or Hyperlipoproteinemia is elevated levels of any or all forms of lipids and/or lipoproteins in the blood. Dyslipidemias include hyperlipidemias (hypercholesterolemia) and low levels of HDL [5]. It is well established that LDL and VLDL levels are the major independent risk factors for cardiovascular events [6]. Free radicals or reactive oxygen species (ROS) are generated naturally in the cell following stress or respiration and also produced by radiation, bacterial and viral toxins, smoking, alcohol and psychological or emotional stress. Antioxidants are the defense mechanism that provides protection against oxidative damage caused by ROS and includes compounds to remove or repair damaged molecules [7]. Herb is an immeasurable wealth of nature both in environmental and medicinal point of view. It plays an important role in ameliorating the disease-resistant ability and combating against various unfavorable metabolic activities within the living system [8].

I. aquatica (synonym: Ipomoea reptans Linn.) belongs to family Convolvulaceae is a perennial herb found throughout India, Sri
Lanka, Tropical Asia, Africa, and Australia. Phytochemical studies have shown the presence of many phytochemical constituents of therapeutic importance such as polyphenols (myricetin, quercetin etc), flavonoids, carotenoids (beta-carotene, violaxanthin, neoxanthin A and B, flavoxanthin etc), terpenoids (phytol, palmitic acid, alpha humulene etc) and several vitamins, minerals, carbohydrates, fats, proteins and amino acids. There are many traditional uses of Ipomoea aquatica Forks plant. It is used as a carminative agent, can be used for the treatment of fever, bronchitis, biliousness and liver complaints. It is also effectively used in leucoderma, leprosy, worm infestation and against nose bleeding and high blood pressure. It is supposed to possess an insulin-like principle according to indigenous medicine in Sri Lanka [9]. As yet there is very little study has been done on its hypolipidemic and antioxidant activities, the present study has been undertaken for detailed study of its above-mentioned properties scientifically.

\section{MATERIALS AND METHODS}

\section{Plant material}

Ipomoea aquatica Forsk. Plants were collected from areas in and around Dibrugarh, Assam. The plant was identified by Prof. L. R. Saikia of Department of Life Sciences, Dibrugarh University. A specimen of the plant bearing voucher number DU L. Sc 436 was preserved in the herbarium of Dibrugarh University. The plant extract was prepared by using percolation method.

\section{Animals}

Healthy New Zealand white rabbit (Oryctolagus cuniculus) of either sex weighing 1.5-2.5 kg were taken and approval was taken from Institutional Animal Ethical Committee (IAEC) of Department of Pharmaceutical Sciences, Dibrugarh University, Dibrugarh, Assam (Reg. No.: 1576/GO/a/11/CPCSEA dated 17/02/2012) vide 
approval number IAEC/DU/74.

They were kept under standard housing conditions in standard cages and maintained under normal room temperature on the standard animal diet consisting of bengal gram, wheat, maize, and carrot in sufficient quantity and water was provided ad libitum during the entire period of the experiment.

\section{Diet used in the study}

1) Normal diet: a Standard animal diet consisting of a bengal gram, wheat, maize, and carrot in sufficient quantity and water $a d$ libitum.

2) High Fat Diet: Mixture of coconut oil (from Marico Industries Ltd., Mumbai) and vanaspati ghee (from Ruchi Industries, Mumbai) in a ratio of 2: $3(\mathrm{v} / \mathrm{v})$ at a dose of $10 \mathrm{ml} / \mathrm{kg}$ body weight per day [10].

\section{Drugs and reagents}

1) Atorvastatin was obtained from Lupin LTD., Kartholi, Jammu.

2) The kits for estimation of HDL-cholesterol, total cholesterol and triglyceride were obtained from Crest Biosystems, Goa, India.

3) Potassium phosphate buffer, hydrogen peroxide solution and tricarboxylic acid were obtained from Sigma Private Limited, Bangalore, India.

4) Thiobarbituric acid was obtained from HiMedia Laboratories Private Limited, Mumbai, India.

\section{Phytochemical screening}

EEIAWP was subjected to qualitative phytochemical analysis for alkaloids, flavonoids, tannins, saponins, diterpenes, triterpenes and phenols as per the standard methods [11].

\section{Acute oral toxicity test}

Acute oral toxicity test for the ethanolic extract of Ipomoea aquatica whole plant (EEIAWP) was carried out as per OECD guidelines 425 [12]. The limit test at $2000 \mathrm{mg} / \mathrm{kg}$ body weight was performed.

\section{Method of preparation of atorvastatin suspension}

The stock solution was prepared by mixing $2.1 \mathrm{mg}$ of atorvastatin powder in $5 \mathrm{ml}$ of normal saline to get a suspension of $0.42 \mathrm{mg}$ atorvastatin in $1 \mathrm{ml}$ of that suspension. The daily dose of atorvastatin $(2.1 \mathrm{mg} / \mathrm{kg} / \mathrm{day})$ for rabbit was calculated by extrapolation from the human dose (80 mg/day) as described by Ghosh MN [13].

\section{Method of preparation of EEIAWP suspension}

The stock solution was prepared by mixing $400 \mathrm{mg}$ of EEIAWP extract powder in $4 \mathrm{ml}$ of distilled water to get a suspension of 100 $\mathrm{mg}$ EEIAWP in $1 \mathrm{ml}$ of that suspension.

\section{Experimental design}

Twenty rabbits were taken and divided into four groups of 5 animals in each and treated as following:

Group-A: Normal Control-received normal diet.

Group-B: Experimental Control-received high-fat diet at a dose of $10 \mathrm{ml} / \mathrm{kg}$ body weight per day mixed with a normal diet.

Group-C: Test drug-received high-fat diet mixed with normal diet plus ethanolic extract of the whole plant of Ipomoea aquatica Fork. (EEIAWP) at a dose of $400 \mathrm{mg} / \mathrm{kg} /$ day orally.

Group-D: Standard Drug-received high-fat diet mixed with normal diet plus Atorvastatin at a dose of $2.1 \mathrm{mg} / \mathrm{kg} /$ day per orally [13].

The animals were treated for a period of $12 \mathrm{w}$. Weight of each animal was taken at the beginning of the experiment and at the end of $12 \mathrm{w}$.

\section{Collection of blood}

Under all aseptic conditions, blood samples were collected from the animals. $5 \mathrm{ml}$ blood was taken from each animal via marginal ear vein [14] and collected in separate plain vials where they were kept for some time. Serum from the blood after clotting was separated out and collected in a clean centrifuge tube and centrifuged for $5 \mathrm{~min}$ at $3000 \mathrm{rpm}$. The serum thus obtained was used for biochemical estimation.

\section{Biochemical analysis}

Lipid profile was done by using the colorimetric method.

- Total cholesterol was measured by CHOD/PAP method [15].

- Triglyceride was measured by GPO/PAP method [16].

- High-density lipoprotein (HDL-Cholesterol) was measured by PEG precipitation method [17].

- Low-density lipoprotein (LDL-Cholesterol) was calculated by using Friedewald's formula [18].

- Atherogenic index of plasma (AIP) is the logarithmically transformed ratio of molar concentrations of triglyceride to HDL cholesterol or log (TG/HDL-C) [19].

\section{Oxidative markers}

- Catalase was measured in blood by Beers and Sizer method by continuous spectrophotometric rate determination [20].

- Superoxide dismutase (SOD) was measured by Kakkar et al. method by continuous spectrophotometric rate determination [21].

- Malondialdehyde (MDA) was measured by TBA method by using filter photo colorimeter [22].

\section{Statistical analysis}

The results of serum lipid profile and oxidative parameters were statistically analyzed using one-way analysis of variance (ANOVA) followed by Bonferroni's multiple comparison tests. The changes in body weights of different groups were analyzed using one-way ANOVA followed by Bonferroni's multiple comparison tests, and initial and final body weights were analyzed using paired $t$-test. The statistical analysis was done using computerized GraphPad Prism software version 5.00. Values were expressed as mean \pm standard error of means (SEM). Values with $p<0.05$ were considered significant.

\section{RESULTS}

Phytochemical analysis of EEIAWP showed the presence of alkaloids, flavonoids, tennins, phytosterols and phenols.

\section{Acute toxicity study}

No mortality was recorded among the rats at the maximum dose of $2000 \mathrm{mg} / \mathrm{kg}$ body weight (all 5 animals survived at $2000 \mathrm{mg} / \mathrm{kg}$ ). Hence, the LD50 can be said to be above $2000 \mathrm{mg} / \mathrm{kg}$. Two-tenth $(400$ $\mathrm{mg}$ ) of this maximum dose tested was selected for the experiments arbitrarily.

\section{Effects of EEIAWP on serum lipid profile in rabbits fed with high fat diet}

After $12 \mathrm{w}$ of treatment with the test drug EEIAWP, the Group C animals (test drug group) showed significant reduction in total serum cholesterol $(72.22 \pm 2.663)$, serum triglycerides $(106.8 \pm 2.853)$ and serum LDL $(26.08 \pm 1.474)$ levels and significant increase in the serum HDL $(27.49 \pm 1.469)$ when compared to the Group B (experimental control group). The AIP was also significantly reduced in the test drug group $(0.2291 \pm 0.025)$ compared to the experimental control group. Table 1 shows serum lipid profile in different groups of the experimental design.

\section{Effects of EEIAWP on serum oxidative markers in rabbits fed with high fat diet}

There were a significant increase in the serum catalase $(292.6 \pm 2.325)$ and serum SOD activities $(4.478 \pm 0.045)$, and there was also a significant reduction in serum MDA levels $(4.998 \pm 0.218)$ in the EEIAWP treated animals when compared to the experimental control group. 
Table 1: Serum lipid profile in different groups

\begin{tabular}{|c|c|c|c|c|c|}
\hline \multirow[t]{2}{*}{ Group } & \multicolumn{4}{|l|}{ Lipid profile (mg/dl) } & \multirow{2}{*}{$\begin{array}{l}\text { Test result (in Ratio) } \\
\text { AIP }\end{array}$} \\
\hline & $\begin{array}{l}\text { Serum total } \\
\text { cholesterol }(\mathrm{mg} / \mathrm{dl})\end{array}$ & $\begin{array}{l}\text { Serum Triglycerides } \\
(\mathrm{mg} / \mathrm{dl})\end{array}$ & $\begin{array}{l}\text { Serum High Density } \\
\text { Lipoproteins (mg/dl) }\end{array}$ & $\begin{array}{l}\text { Serum Low Density } \\
\text { Lipoproteins } \\
\text { (mg/dl) }\end{array}$ & \\
\hline Normal Control & $43.29 \pm 1.851$ & $60.58 \pm 3.294$ & $25.53 \pm 0.776$ & $13.55 \pm 0.891$ & $0.0514 \pm 0.013$ \\
\hline $\begin{array}{l}\text { Experimental } \\
\text { Control }\end{array}$ & $108.9 \pm 3.530^{\mathrm{a}}$ & $176.7 \pm 5.711^{\mathrm{a}}$ & $12.48 \pm 0.995^{\mathrm{a}}$ & $58.14 \pm 4.228^{a}$ & $0.7942 \pm 0.0468^{a}$ \\
\hline Test Drug & $72.22 \pm 2.663^{\mathrm{b}}$ & $106.8 \pm 2.853^{b}$ & $27.49 \pm 1.469^{b}$ & $26.08 \pm 1.474^{b}$ & $0.2291 \pm 0.025^{b}$ \\
\hline Standard Drug & $67.93 \pm 1.596^{b}$ & $106.8 \pm 4.501^{\mathrm{b}}$ & $30.71 \pm 0.984^{b}$ & $22.43 \pm 1.647^{\mathrm{b}}$ & $0.1786 \pm 0.0261^{\mathrm{b}}$ \\
\hline
\end{tabular}

Values are expressed as mean \pm SEM $(n=5)$. One way ANOVA followed by Bonferroni's multiple comparison test is done. ${ }^{a}=p<0.05$, when compared to the normal control group. ${ }^{b}=p<0.05$, when compared to the experimental control group.

Table 2: Serum oxidative markers in different groups

\begin{tabular}{llll}
\hline Groups & Catalase $(\boldsymbol{\mu m o l} / \mathbf{m i n} / \mathbf{m l})$ & SOD $(\mathbf{u} / \mathbf{m g}$ protein) & Malondialdehyde $(\mathbf{n m o l} / \mathbf{m l})$ \\
\hline Normal Control & $245.8 \pm 3.680$ & $4.180 \pm 0.049$ & $4.900 \pm 0.125$ \\
Experimental Control & $184.1 \pm 2.910^{\mathrm{a}}$ & $2.080 \pm 0.037^{\mathrm{a}}$ & $7.266 \pm 0.112^{\mathrm{a}}$ \\
Test Drug & $292.6 \pm 2.325^{\mathrm{b}}$ & $4.478 \pm 0.045^{\mathrm{b}}$ & $4.998 \pm 0.218^{\mathrm{b}}$ \\
Standard Drug & $236.0 \pm 3.029^{\mathrm{b}}$ & $4.084 \pm 0.073^{\mathrm{b}}$ & $4.682 \pm 0.176^{\mathrm{b}}$ \\
\hline
\end{tabular}

Values are expressed as mean \pm SEM ( $n=5$ ). One way ANOVA followed by Bonferroni's multiple comparison tests was done. ap $<0.05$, when compared to the normal control group. ${ }^{\mathrm{b}} \mathrm{p}<0.05$, when compared to the experimental control group

\section{Effects on body weight in treated rabbits}

The body weights of the normal control, experimental control, test drug group and standard drug group were initially 1694 \pm 51.07 , $1662 \pm 52.81,1592 \pm 30.47$ and $1617 \pm 19.28$ g respectively and after $12 \mathrm{w}$, they were $1720 \pm 11.18,1939 \pm 28.53,1711 \pm 20.22$ and $1721 \pm 22.91 \mathrm{~g}$ respectively. The differences in their baseline body weights were found to be non-significant $(p>0.05)$

The final body weight after $12 \mathrm{w}$ of treatment showed a significant increase in experimental control $(16.67 \%)$ and test drug group $(7.47 \%)(p<0.0)$, but the increase in normal $(1.55 \%)$ and standard drug groups $(2.99 \%)$ were statistically not significant $(p>0.05)$. It was observed that there was a significant difference in weights of the rabbits in normal and experimental control groups after $12 \mathrm{w}$ of the experiment. There was also a significant difference when the test and the standard drug groups were compared to the experimental control group $(p<0,05)$. Table 3 shows the effect of EEIAWP on body weights of rabbits.

Table 3: Effects on body weights in treated rabbits

\begin{tabular}{|c|c|c|c|c|c|}
\hline \multirow[t]{2}{*}{ Groups } & \multicolumn{5}{|c|}{ Mean body weight (g) } \\
\hline & On $1^{\text {st }}$ day & After $12^{\text {th }}$ week & Change & $\%$ of increase & $\%$ of decrease \\
\hline Normal Control & $1694 \pm 51.07$ & $1720 \pm 11.18$ & 26 & 1.55 & -- \\
\hline Experimental Control & $1662 \pm 52.81$ & $1939 \pm 28.53^{\mathrm{a}}$ & 277 & 16.67 & -- \\
\hline Test Drug & $1592 \pm 30.47$ & $1711 \pm 20.22^{\mathrm{b}}$ & 119 & 7.47 & -- \\
\hline Standard Drug & $1617 \pm 19.28$ & $1721 \pm 22.91^{b}$ & 104 & 2.99 & -- \\
\hline
\end{tabular}

Values are expressed as mean \pm SEM $(n=5)$. Paired t-test was done. a $p<0.05$, when compared to the normal control group. ${ }^{b} p<0.05$, when compared to the experimental control group

\section{DISCUSSION}

There was significant increase in the total serum cholesterol, LDL cholesterol, triglyceride and marked reduction in the HDL cholesterol levels in the rabbits fed on with high-fat diet for $12 \mathrm{w}$. M. T. Sampath kumar et al., 2011[23] in their study found similar results for TC, TG, LDL-C, and HDL-C levels in hyperlipidemic rats treated with vehicle alone without the T. pallida fruits ethanolic extracts. Asgary S et al. [24] also found similar results for TC, TG, and LDL-C in their hypercholesterolemic diet group. However, HDL-C was also significantly higher as compared to the normal diet group in their study. Similarly, oxidative markers such as catalase and SOD activities were significantly reduced and MDA levels were significantly raised in the experimental control group after $12 \mathrm{w}$ of treatment with high-fat diet.

Animals treated with EEIAWP showed a significant reduction in the total cholesterol, triglyceride and LDL and significantly raised HDL levels after the experiment. Serum catalase and SOD activities were also increased significantly and MDA level was reduced markedly in the animals treated with the test drug.

Polyphenols are phytochemicals present in vegetables and fruits which constitute a large group of natural antioxidants. Polyphenols possess many pharmacological properties. They trap and scavenge free radicals, regulate nitric oxide, decrease leukocyte immobilization, induce apoptosis, inhibit cell proliferation and angiogenesis, and exhibit phytoestrogen activity. These effects may contribute to their potentially protective role in cancer and CVDs [25]. Zern et al. (2005) in their study in on the effects of grape polyphenols in pre-and postmenopausal women found that naringenin, a grapefruit flavonoid, decreased ApoB secretion, thereby reducing the concentration of TG secretion. Lyophilized grape powder (LGP) that was used in the study also decreased hepatic acyl-CoA cholesterol acyl transferase activity, an important enzyme involved in the packaging of VLDL [26]. There is a strong association between the risk of Coronary Artery Disease (CAD), high levels of LDL-C and low levels of HDL-C [27, 28]. Isolated elevation in triglycerides increases the risk of CAD but its effect is counteracted by the levels of HDL-C. The AIP, which is a mathematical relationship between TG and HDL-C has been successfully used as an additional index when assessing cardiovascular risk factors [19]. It has been suggested that AIP values of- 0.3 to 0.1 are associated with low, 0.1 to 0.24 with medium and above 0.24 with a high risk of CVD [29]. In our study we found the AIP of the experimental control group is very high $(\sim 0.8)$. But in the EEIAWP and atorvastatin-treated groups, the AIP was reduced significantly compared to the experimental control 
group ( $\sim 0.23$ and $\sim 0.18$ respectively) though still came under the medium risk category. Oxidative modification of low-density lipoproteins (LDL) by free radicals is an early event in the pathogenesis of atherosclerosis which is an important sequel of hyperlipidemia. Oxidized LDL promotes the atherosclerotic process through lipid accumulation, focal necrosis, connective tissue proliferation and other sub-parenchymal events. Minimally oxidized LDL may be a local mediator promoting thrombosis in atherosclerotic lesions. A number of mechanisms are likely to contribute to the inhibition of LDL oxidation by flavonoids. Flavonoids may directly scavenge some radical species by acting as chain-breaking antioxidants. In addition, they may recycle other chain-breaking antioxidants such as $\alpha$-tocopherol by donating a hydrogen atom to the tocopheryl radical. Flavonoids also directly inhibit catalytic activities of cell-surface enzymes such as NADH oxidase, cyclooxygenase and cytochrome $\mathrm{C}$ oxidase in the systems that are involved in the initiation or propagation of peroxidative products/processes [30,31]. In different studies, several workers have reported a decrease in the lipogenic enzymes activity in cholesterol-fed animals treated with flavonoids. A significant increase of lipoprotein lipase and lecithin acyltransferase (LCAT) on feeding Ficus bengalensis flavonoids and quercetin to such groups was seen by Daniel et al. [32]. Work done by Nichols et al. [33] showed that citrus flavonoids regulated the transcription of the lowdensity lipoprotein receptor (LDLR) gene in HepG2 cells leading to their hypo-cholesterolemic effects.

Phytosterols are naturally occurring plant sterols that are structurally similar to cholesterol. They possess hypolipidemic effect by reducing intestinal cholesterol absorption thereby enhancing fecal cholesterol excretion and reducing serum LDL-cholesterol concentrations. Racette et al. studied the effects of moderate (459 $\mathrm{mg} / \mathrm{dl})$ and high $(2059 \mathrm{mg} / \mathrm{dl})$ dosage of phytosterols in human volunteers aged $18-80 \mathrm{y}$ and found that both the moderate and high phytosterol intakes had a large effect on cholesterol excretion [34].

With the aid of the above literature, we can hypothesize that the antihyperlipidemic activity of I. aquatica could be attributed, to the hypolipidemic activities of various polyphenols and flavonoids, phytosterols and plant proteins present in the plant extract.

MDA is a product of lipid peroxidation caused due to the reaction of free radicals (hydroxyl radical) with polyunsaturated fatty acid moieties of the cell membrane phospholipids and causes damage to cell [35]. The antioxidant enzymes, mainly superoxide dismutase and catalase are the first line defensive enzymes against free radicals. It is well known that flavonoids and polyphenols are natural antioxidants which also significantly increase superoxide dismutase and catalase activities [36]. Antioxidant actions also appear to mediate through $\mathrm{H}^{+}$donating property and ability to chelate redox-active metal ions. Jeong et al. demonstrated marked inhibition of oxidation of LDL incubated in $5 \mu \mathrm{M}-\mathrm{Cu}^{2+}$ alone or in combination with human umbilical vein endothelial cells (HUVEC) in the presence of various flavonoids, by inhibiting the formation of per oxidative products [31]. In a different study by Vázquez-Castilla et al. [37] suggested that flavonoids could be the main compounds involved in preventing lipid peroxidation and decreasing MDA levels.

The final body weight of rabbits in all the study groups was increased than their initial body weight. The increase was significant only in the experimental control and the drug test groups while there was no significant increase in the normal control and the standard drug groups. When compared to the experimental control group the body weight of the test drug group was significantly less after $12 \mathrm{w}$.

Tannins are reported to be involved in growth regulations. Tannins could potentially inhibit the activity of lipases thereby lowering the body fat content [38]. The weight lowering potential of I. aquatica could at least partially be attributed to the presence of tannins found in the plant.

\section{CONCLUSION}

Hyperlipidemia and growing incidence of CVDs is a matter of great concern at present and prevention remains the mainstay of its management. I. aquatica showed a significant reduction in the serum lipid levels and antioxidative properties which may be attributed to the presence of different medically important phytochemicals such as flavonoids, phytosterols, etc. Thus, it can be concluded that Ipomoea aquatica Forsk. the plant which are easily available in India and in several parts of the world hold enormous potential for the development of a new drug for the prevention and treatment of dyslipidemia. However, there is a need for further elaborate studies on bigger experimental animals and human beings. That may provide more definitive data regarding its therapeutic potential and exact mode of action.

\section{ACKNOWLEDGEMENT}

This work was supported by funds from Department of Biotechnology for their financial assistance for the research work under thesis grant for MD/MS students from the North-Eastern Region.

\section{CONFLICT OF INTERESTS}

\section{Declared none}

\section{REFERENCES}

1. Dubey AK, Devi A, Kutty G, Shankar RP. Hypolipidemic activity of ginkgo biloba extract, Egb 761 in hypercholesterolemia wistar rats. Iranian J Pharmacol Ther 2004;4:9-12.

2. Gopa B, Bhatt J, Hemavathi K. A comparative clinical study of the hypolipidemic efficacy of Amla (Emblica officinalis) with 3hydroxy-3-methylglutaryl-coenzyme-A reductase inhibitor simvastatin. Indian J Pharmacol 2012;44:238-42.

3. Ranjani H, Pradeepa R, Mehreen TS, Anjana RM, Anand K, Garg $\mathrm{R}$, et al. Determinants, consequences, and prevention of childhood overweight and obesity: an Indian context. Indian J Endocrinol Metab 2014;18:17-25.

4. Wikipedia. Obesity [Internet]; 2014. Available from: http:// en.wikipedia.org/wiki/Obesity. [Last accessed on 26 Jun 2015].

5. Bersot TP. Drug therapy for hypercholesterolemia and dyslipidemia. In: Brunton LL, Chabner BA, Knollmann BC. editors. Goodman and Gillman's The Pharmacological Basis of Theraputics. $12^{\text {th }}$ ed. New Delhi: McGraw-Hill; 2011. p. 877-908.

6. Deng R, Chow TJ. Hypolipidemic, antioxidant, and antiinflammatory activities of microalgae Spirulina. Cardiovasc Ther 2010;28:33-45.

7. Jayachitra A, Krithiga N. Study on antioxidant property in selected medicinal plant extracts. Med Aromat Plants 2012;2:495-500.

8. J Bhakta, P Majumdar, Y Munekage. Antimicrobial efficacies of methanol extract of Asteracantha longifolia, Ipomoea aquatica and Enhydra fluctuans against Escherichia coli, Pseudomonas aeruginosa, Staphylococcus aureus and Micrococcus luteus. Internet J Alternative Med 2008; 7:1-6.

9. Manvar MN, Desai TR. Phytochemical and pharmacological profile of Ipomoea aquatica. Indian J Med Sci 2013;67:49-60.

10. Shyamala MP, Venukumar MR, Latha MS. Antioxidant potential of the Syzygium aromaticum (Gaertn.) Linn. (cloves) in rats fed with high-fat diet. Indian J Pharmacol 2003;35:99-103.

11. Tiwari P, Kumar B, Kaur M, Kaur G, Kaur H. Phytochemical screening and extraction: a review. Int Pharm Sci 2011;1:98-106.

12. Organization for Economic Cooperation and Development (OECD) Guidelines for the testing of chemicals 425. Adopted; 2008. p. 1-4.

13. Ghosh MN. Toxicity studies. Fundamentals of Experimental Pharmacology. $5^{\text {th }}$ ed. Kolkata: Hilton and Company; 2008. p. 165-72.

14. The University of Toledo. Guidelines for blood collection: Rodents and Rabbits; 2011. p. 1-7.

15. Allain C, Poon L, Chan C, Richmond W, Fu P. Enzymatic determination of serum total cholesterol. Clin Chem 1974; 20:470-5.

16. Fossati P, Prencipe L. Serum triglycerides determined colorimetrically with an enzyme that produces hydrogen peroxide. Clin Chem 1982; 28:2077-80.

17. Grillo F, Izzo C, Mazzotti G, Murador E. Improved method for determination of high-density-lipoprotein cholesterol II. Enzymatic determination of cholesterol in high-density lipoprotein fractions with a sensitive reagent. Clin Chem 1981;27:375-9. 
18. Friedewald W, Levy R, Fredrickson D. Estimation of the concentration of low-density lipoprotein cholesterol in plasma, without the use of the preparative ultracentrifuge. Clin Chem 1972;18:499-502.

19. Nwagha UI, Ikekpeazu EJ, Ejezie EE, Maduka IC. Atherogenic index of plasma as a useful predictor of cardiovascular risk among postmenopausal women in Enugu, Nigeria. Afr Health Sci 2010;10:248-52.

20. Beers R, Sizer I. A spectrophotographic method for measuring the breakdown of hydrogen peroxide by catalase. J Biol Chem 1952;195:133-40.

21. Kakkar P, Das B, Viswanathan PM. A modified spectrophotometric assay of superoxide dismutase. Indian J Biochem Biophys 1984;21:130-2.

22. Satoh K. Serum lipid peroxide in cerebrovascular disorders determined by a new colorimetric method. Clin Chim Acta 1978; $90: 37-43$.

23. Sampathkumar MT, Kasetti RB, Nabi SA, Sudarshan PR, Swapna S, Apparao C. Antihyperlipidemic and antiatherogenic activities of Terminalia pallida Linn. fruits in high-fat diet induced hyperlipidemic rats. J Pharm Bioallied Sci 2011;3:449-52.

24. Asgary S, Rafieian-Kopaei M, Najafi S, Heidarian E, Sahebkar A. "Antihyperlipidemic effects of Sesamum indicum L. in rabbits fed a high-fat diet". Sci World J 2013. http://dx.doi.org/ $10.1155 / 2013 / 365892$

25. Arts ICW, Hollman PCH. Polyphenols and disease risk in epidemiologic studies ${ }^{1-4}$. Am J Clin Nutr 2005;81:317S-25S.

26. Zern TL, Wood RJ, Greene C, West KL, Liu Y, Aggarwal D, et al. Grape polyphenols exert a cardioprotective effect in pre-and postmenopausal women by lowering plasma lipids and reducing oxidative stress. J Nutr 2005;135:1911-7.

27. Castelli WP, Anderson K, Wilson PW, Levy D. Lipids and risk of coronary artery disease. The Framingham Study. Ann Epidemol 1992;2:23-8.

28. Igweh JC, Nwagha IU, Okaro JM. The effects of menopause on the serum lipid profile of normal females of south-east Nigeria. Nigerian J Physiol Sci 2005;20:48-53.

29. Dobiasova M. AIP-atherogenic index of plasma as a significant predictor of cardiovascular risk: from research to practice. Vnitr Lek 2006;52:64-71.
30. Narayana K, Reddy M, Chaluvadi M, Krishna D. Bioflavonoids classification, pharmacological, biochemical effects and therapeutic potential. Indian J Pharmacol 2001;33:2-16.

31. Jeong YJ, Choi YJ, Kwon HM, Kang SW, Park HS, Lee M, et al. Differential inhibition of oxidized LDL-induced apoptosis in human endothelial cells treated with different flavonoids. $\mathrm{Br} \mathrm{J}$ Nutr 2005;93:581-91.

32. Daniel R, Devi K, Augusti K, Nair C. Mechanism of action of antiatherogenic and related effects of Ficus bengalensis Linn. flavonoids in experimental animals. Indian J Exp Biol 2003;41:296-303.

33. Nichols LA, Jackson DE, Manthey JA, Shukla SD, Holland LJ. Citrus flavonoids repress the mRNA for stearoyl-CoA desaturase, a key enzyme in lipid synthesis and obesity control, in primary rat hepatocytes. Lipids Health Dis 2011;10:36.

34. Racette SB, Lin X, Lefevre M, Spearie CA, Most MM, Ma L, et al. Dose effects of dietary phytosterols on cholesterol metabolism: a controlled feeding study. Am J Clin Nutr 2010;91:32-8.

35. Saeed N, Khan MR, Shabbir M. Antioxidant activity, total phenolic and total flavonoid contents of the whole plant extracts Torilis leptophylla L. BMC Complementary Altern Med 2012;12:221-32.

36. Visavadiya NP, Narasimhacharya AVRL. Hypolipidemic and antioxidant activities of Asparagus racemosus in hypercholesteremic rats. Indian J Pharmacol 2005;37:376-80.

37. Vazquez-Castilla $S$, De la Puerta $R$, Garcia-Gimenez $M$, Fernandez-Arche M, Guillen-Bejarano R. Bioactive constituents from "Triguero" Asparagus improve the plasma lipid profile and liver antioxidant status in hypercholesterolemic rats. Int J Mol Sci 2013;14:21227-39.

38. Chichioco-Hernandez C, Leonido F. Weight-lowering effects of Caesalpinia pulcherrima, Cassia fistula and Senna alata leaf extracts. J Med Plants Res 2011;5:452-5.

\section{How to cite this article}

- Aziz Sahid, Gohain Kalpana. A study of the hypolipidemic and antioxidant activities of whole plant extracts of Ipomoea aquatica forsk in experimentally induced hyperlipidemia in rabbits. Int J Pharm Pharm Sci 2016;8(10):265-269. 